\title{
Effect of Group Size and Individual Characteristics on Intergroup Encounters in Primates
}

\author{
Bonaventura Majolo $^{1}$ (D) A Aurora deBortoli Vizioli ${ }^{2} \cdot$ Laura Martínez-Íñigo $^{1}$ • \\ Julia Lehmann ${ }^{3}$
}

Received: 20 May 2019 / Accepted: 8 November 2019 / Published online: 6 January 2020

(C) The Author(s) 2020

\begin{abstract}
Intergroup encounters are common in nonhuman primates and can vary from affiliative to aggressive. We extracted data from the literature to test five different hypotheses: 1) where there are group size differences between opposing groups, whether the larger group is more likely to win an intergroup encounter than the smaller group; 2) whether the likelihood of a group engaging in aggressive intergroup encounters increases with group size; and 3-5) whether dominant, older individuals, and/or males are more likely to participate aggressively in intergroup encounters than subordinate, younger individuals and/or females. Our data set comprised 52 studies on 31 primate species (3 lemur species, 5 New World monkeys, 19 Old World monkeys, and 4 apes). We found that the larger group is more likely to win an encounter against a smaller group than vice versa. We found no significant relationship between group size and propensity to be aggressive during intergroup encounters. We found weak/no support for the effect of age, dominance rank, and sex on the frequency of aggression displayed toward outgroup individuals during intergroup encounters. Species- and population-specific differences in inter- and intragroup competition and in the degree of the unequal distribution of resources across group members may explain why age, dominance rank, and sex are not strong predictors of aggression during intergroup encounters.
\end{abstract}

Keywords Aggression · Competition · Conflict · Group size · Intergroup encounter · Rank

Handling Editor: Cyril Grueter

Electronic supplementary material The online version of this article (https://doi.org/10.1007/s10764-01900119-5) contains supplementary material, which is available to authorized users.

Bonaventura Majolo

bmajolo@lincoln.ac.uk

1 School of Psychology, University of Lincoln, Lincoln, UK

2 Institute of Cognitive Sciences and Technologies, National Research Council, Rome, Italy

3 CRESIDA, University of Roehampton, London, UK 
Encounters between conspecific groups are common in group-living species (e.g., Kitchen and Beehner 2007; Mech 1988; Radford and Fawcett 2014; Thompson et al. 2017). In recent years, there has been growing research on the causes and consequences of intergroup encounters (IGEs) in nonhuman primates (e.g., Cooper et al. 2004; Kitchen et al. 2004; Koch et al. 2016; Majolo et al. 2005; Markham et al. 2012; Willems and van Schaik 2015; Wilson et al. 2001). During IGEs, members of the distinct groups can ignore/avoid each other, mate, or exchange affiliative or aggressive behaviors of variable intensity; often several of these behaviors are observed during the same encounter, displayed by different individuals or by the same animals at different times or toward different targets (Arseneau-Robar et al. 2017; Furuichi 2019). In nonhuman primates, the number of aggressive IGEs that a group engages in per day is positively related to group size (this relationship being stronger in arboreal than in terrestrial species), territoriality, and with home-range overlap (Willems and van Schaik 2015). Aggressive IGEs are expected to be caused by competition over valuable resources (Sterck et al. 1997). Winning an IGE can give group members various fitness-related benefits, including access to the contested resource, territory/home range expansion, or mating opportunities (Radford and Fawcett 2014; Wilson and Wrangham 2003). At the same time, IGEs can also result in severe injuries and death (Mitani et al. 2010; Tórrez-Herrera et al. 2019), especially for members of the group losing the encounter.

For some of the resources at stake during aggressive IGEs (e.g., territory expansion/ contraction), the benefits/costs of winning/losing a IGE are shared about equally by all group members (Crofoot 2013; Kitchen and Beehner 2007). However, in the same cases, the costs of an aggressive IGE may differ depending on individual participation (e.g., animals closer to the opposing group and more actively involved in the IGE are at greater risk of injury). Under these conditions, IGEs pose a collective action problem and the risk of free riding can be high (Crofoot and Gilby 2012; Nunn 2000; Nunn and Deaner 2004; Willems et al. 2013; Willems and van Schaik 2015). Thus, the outcome of an aggressive IGE depends on the interplay of several different factors at the group and at the individual level (Kitchen and Beehner 2007). According to game theory, at the group level the likelihood of winning an IGE is expected to depend on the resourceholding potential of the opposing groups (i.e., relative competitive power, measured as the number of adults in each group and/or their fighting ability), on how many individuals from each group take part in the encounter and on the expected payoff of the IGE (Kitchen and Beehner 2007; Maynard Smith 1974; Maynard Smith and Parker 1976; Maynard Smith and Price 1973; Parker 1974; Wrangham 1980). Larger groups are predicted to be dominant over and win IGEs against smaller groups (Cooper et al. 2004), other things being equal (e.g., IGE location or resource at stake; Brown 2013; Crofoot et al. 2008; Gilby et al. 2013; Willems and van Schaik 2015). This might be because the larger the group size difference between two opposing groups, the lower is the risk of injury for each group member of the larger group due to numeric advantage and/or dilution effects (Wrangham 1999). Thus, individuals in larger groups should be more likely to take part in aggressive IGEs than those in smaller groups (Kitchen et al. 2004; Langergraber et al. 2017; Mitani and Watts 2005; Van Belle and Scarry 2015; Willems and van Schaik 2015). At the same time, larger groups are more at risk of free riding during IGEs, because the larger the group the lower the benefit that each group member gains by participating in a IGE (Willems et al. 2013). Moreover, in large 
groups it is more difficult to monitor the behavior of group members and coerce their participation in the aggressive IGE (Kitchen and Beehner 2007). If so, a greater proportion of individuals in smaller groups is expected to participate in aggressive IGEs (Bonanni et al. 2010). Moreover, the intensity of aggression during IGEs is expected to depend on the value of the resource and the magnitude of the difference in competitive capacity between the opposing groups. IGEs are more likely to result in intense aggression the closer the competitive capacity of the opposing groups (Mirville et al. 2018) and/or the more valuable the resource at stake.

At the individual level, animals should be more likely to face the potential risks of actively participating in an aggressive IGE, the greater the benefits they gain. Indeed, aggressive interactions between groups may be better described as the result of individual-level decisions, where payoffs for participation (or lack of it) differ across individuals, than as a group-level communal defence of resources (Willems et al. 2015). Age, dominance rank, and sex are three key characteristics affecting individual participation in aggressive IGEs (Kitchen and Beehner 2007). Dominant/adult individuals may gain greater fitness-related benefits than subordinate/younger animals by being aggressive toward outgroup individuals during IGEs, because they should have preferential access to the contested resources if their group wins an IGE (ArseneauRobar et al. 2017; Cooper et al. 2004; Lazaro-Perea 2001; Majolo et al. 2005; Nunn and Deaner 2004; Willems et al. 2015). For example, dominant individuals should be particularly aggressive during IGEs occurring in the mating season, if winning a IGE increases their mating opportunities in comparison to subordinates (Cooper et al. 2004; Majolo et al. 2005). Similarly, adults can gain mating opportunities that are not yet available to sexually immature individuals (Lazaro-Perea 2001). Aggressive IGEs are particularly risky for younger individuals, if they are involved in aggressive confrontations with fully grown animals from the opposing group; thus, younger individuals should be less likely to take part in IGEs than adults. At the same time, subadult animals, and more broadly individuals who are ready to disperse into a new group, can use IGEs to assess the risk of emigrating into a new group and thus could attempt to affiliate with, or be aggressive toward outgroup individuals, when they are ready to disperse (Ishizuka et al. 2019; Majolo et al. 2005; Toda in press). Moreover, it is possible that age-related effects become less prominent once an individual has reached sexual maturity. In relation to sex differences, males are often found to be more aggressive during IGEs than females (Kitchen and Beehner 2007): they can reduce the likelihood of male immigration into their group, maintaining monopolization of their group females and reducing the risk of infanticide, they can gain mating opportunities with outgroup females, and they can protect food sources for their females and themselves (Cooper et al. 2004; Lewis et al. in press; Majolo et al. 2005; Payne et al. 2003). However, female primates can be equally/more aggressive toward outgroup individuals than males when, for example, they are the dominant sex (Koch et al. 2016). Moreover, females avoid the risk of engaging in aggressive interactions with outgroup members by incentivizing their group males to participate in IGEs and by punishing males that do not take part (Arseneau-Robar et al. 2016, 2017).

Despite the growing number of single-species studies on IGEs in nonhuman primates, some qualitative reviews and theoretical frameworks on the topic (Kitchen and Beehner 2007; Radford et al. 2016; Christensen and Radford 2018), there are very few comparative quantitative tests of group- and individual-level factors affecting IGE 
individual participation and outcome (Willems and van Schaik 2015). In light of the large intra- and interspecific differences observed in the social behavior of primates and of the over-/underrepresentation of some species in the literature, testing whether IGEs are affected by similar factors (e.g., dominance status or sex) across primate populations and species is of primary importance. To this end, we used meta-analytical techniques to quantitatively analyze the importance of group size and of individual characteristics (i.e., age, dominance rank, and sex) on aggressive IGEs in nonhuman primates. First, we tested whether there is a significant relationship between group size and how likely an IGE is to be aggressive. If intergroup aggression is less costly for individuals in larger groups, owing to numeric advantage and/or dilution effects, we predicted that there should be a positive relationship between the number of adults and subadults in a group and how likely a group is to exchange aggression with another group. Conversely, if the risk of free riding increases in larger groups, we predicted a negative, or no significant relationship between group size and proportion of aggressive IGEs. Second, for IGEs where opposing groups differ in group size, we predicted that the larger group would be more likely to win an encounter than the smaller group. In the remaining analyses we focused on factors that can explain individual aggressive participation in IGEs. We tested whether older or more dominant individuals are more likely to participate aggressively in IGEs than younger or subordinate individuals. Moreover, we tested the hypothesis that male primates are more likely to participate aggressively in IGEs than females.

\section{Methods}

\section{Data Collection}

We ran a systematic review of the literature on IGEs in nonhuman primates published between January 1965 and November 2018. We used the Web of Science (C) Thomson Reuters Corporation) to search for relevant papers and books, and ProQuest Dissertations \& Theses Global (C) ProQuest LLC.) for PhD/MSc theses. We searched these two databases for any study containing a combination of the following four words in the output's title, abstract or keywords: between-group or inter-group or out-group and aggression or competition or dominance or encounter or interaction or threat or conflict or territorial or contest and primate (Fig. 1). We checked the abstracts of the selected studies to remove findings on non-group-living primates or those that were not relevant for our meta-analysis. From the potentially useful publications, we included only studies on IGEs that contained the data necessary to test our hypotheses (see later). To be included in our meta-analysis, a study had to use a definition of IGEs requiring members from the two groups to be potentially/effectively in visual contact with one another. However, we decided to rely on the study-specific criteria for maximum distance between groups to define an encounter for three reasons. First, there is no general consensus in the literature on what criteria should be used to define an IGE. The majority of studies in our meta-analysis used maximum distance between two groups to define the start/end of an encounter, whereas other studies focused on visual contact between the groups irrespective of their distance from one another. Second, differences across studies in the maximum distance between groups, used to define the start/end of 


\section{PRISMA Flow Diagram}

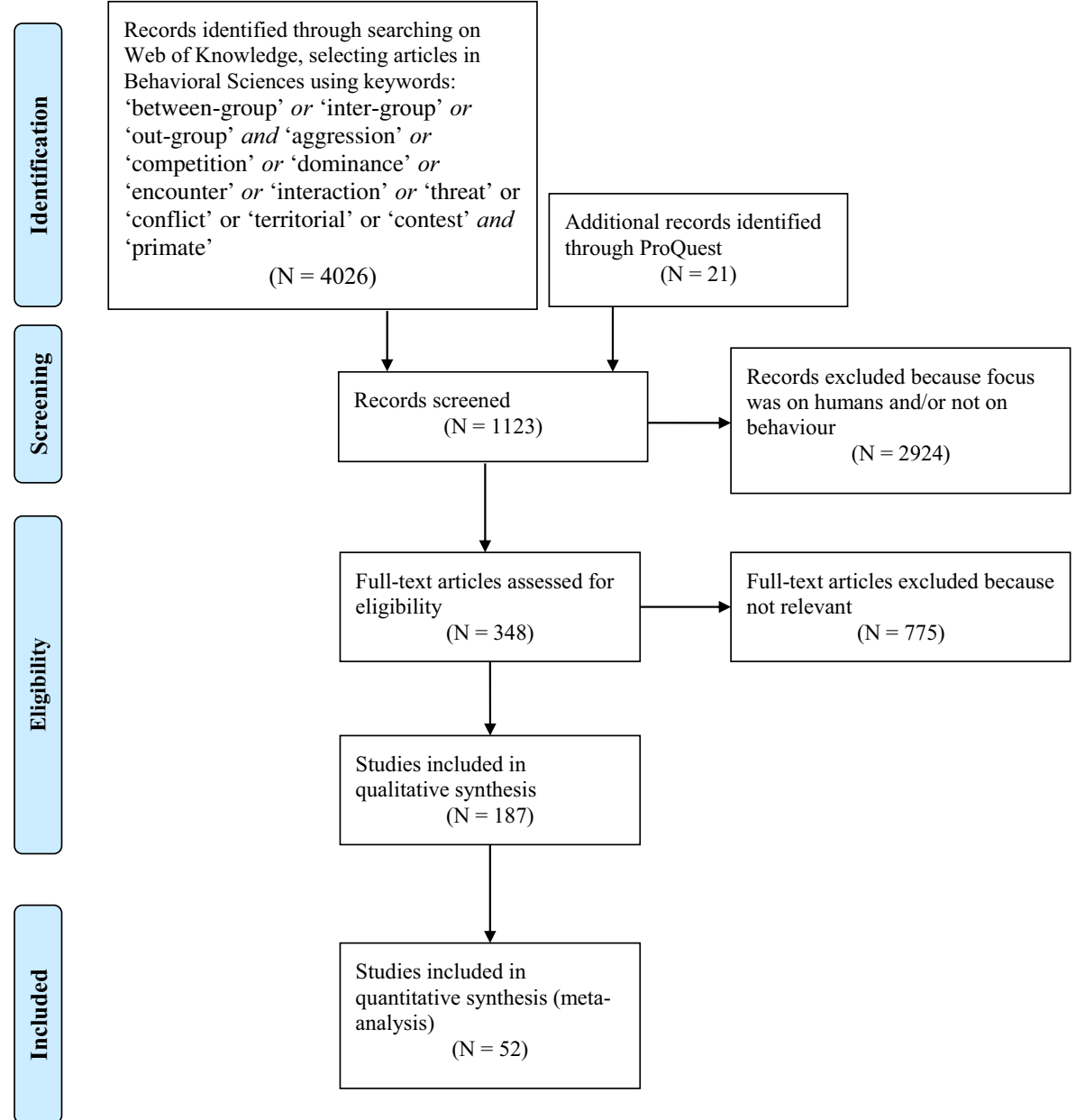

Fig. 1 PRISMA flow diagram (Moher et al. 2009) describing the steps taken, and the number of studies included/excluded at each step, to select the studies included in this meta-analysis. Details of the criteria used to include/exclude studies are in the Methods.

an IGE, were due to the biology of the studied species and their habitat (e.g., habitat characteristics and visibility where the study was conducted, location of IGEs, body size or degree of terrestriality of the study species). For example, IGEs in western lowland gorillas (Gorilla gorilla gorilla) in Lokoue were defined to occur when two groups were at a distance of $\leq 250 \mathrm{~m}$ and potentially in visual contact with one another, because all encounters were observed in forest clearings that had a maximum size of $c a$. $250 \mathrm{~m}$ and good visibility (Caillaud et al. 2008). Conversely, in the subtropical forest of Yakushima Island, Japan, where visibility is relatively poor, two groups of Japanese macaques (Macaca fuscata yakui) had to be within $50 \mathrm{~m}$ for an IGE to be defined to occur (Majolo et al. 2005). Third, in some of the studies included in our meta-analysis, the definition of IGE required members of the opposing groups to interact with one another, but there were no data on the maximum distance between groups to define the 
start/end of an encounter. We included studies on wild or free-ranging but provisioned primates to enlarge our sample size. Conversely, we excluded from our meta-analysis studies in which two distinct groups only interacted through long-distance calls (e.g., Bonadonna in press; Van Belle and Estrada 2019), and studies in which one group was presented with playback calls (or other visual/olfactory stimuli) simulating the presence of another group. We excluded those studies because the outcome of long-distance interactions is often difficult to assess. Moreover, individual participation in longdistance interactions and/or response to playback calls have less/no immediate consequences for individual fitness in comparison to short-distance aggressive interactions. Finally, we excluded all studies conducted in captivity but one (Nunn and Deaner 2004), because in all of the excluded captive studies the two groups were separated by a fence and could not interact freely with one another.

From the studies that met the foregoing criteria, we included in our meta-analysis the studies that contained statistical analyses on, or raw data that allowed us to calculate, at least one of the following five measures: 1) correlation between group size and proportion of aggressive IGEs (i.e., the $N$ of encounters where the two groups exchanged aggression divided by total $N$ of encounters observed); 2) correlation between group size difference between two opposing groups and proportion of IGEs won by the larger group (winning an encounter being defined as one group, the winner, displacing another group, the loser); 3-5) correlation between the age/dominance rank/sex of the individuals and the frequency of their aggressive participation in IGEs. Throughout this article, we use the term group size to refer to the total number of adult and subadult individuals of the two sexes in a group; aggression refers to threats (vocal, facial, or full body displays), chases, slaps, grabs, or bites directed to members of the opposite group. As species in our data set had different behavioral repertoires, we did not use predetermined criteria to define an encounter as aggressive but relied on the speciesspecific aggressive behaviors used by the authors of the primary studies.

\section{Statistical Analyses}

For each study included in our meta-analysis, we extracted the Pearson correlation coefficient for the five relationships described earlier. A positive Pearson correlation coefficient indicated, respectively, that 1) larger groups experienced aggression in a greater proportion of IGEs than smaller groups (hereafter group size-aggression effect'); 2) IGEs were more likely to be won by the larger of the two opposing groups (hereafter group size-outcome effect); 3 ) older individuals were more aggressive than younger individuals (hereafter age effect'); 4) more dominant individuals were more aggressive than less dominant individuals during IGEs (dominance rank effect); 5) males were more aggressive than females during IGEs (hereafter sex difference effect). For studies in which rank was inversely scored (i.e., dominant individuals were assigned a lower number than subordinates) we adjusted the sign of the correlation coefficient so that a positive correlation always indicated greater aggression by dominant individuals. For the data on age and dominance rank effects we also recoded the sex of the study individuals, because the majority of studies that contained relevant data had tested the effect of these factors in just one sex. When a Pearson correlation coefficient for one or more of these relationships was not available in the selected study, we calculated it from raw data available in the studies, using SPSS v. 22.0 (C) 
IBM). For studies from which we could not extract or calculate a Pearson correlation coefficient, we used other statistics (chi-square, $F, t$, or $P$ value) for the relevant relationships and converted these figures into Pearson correlation coefficients using MetaWin Statistical Calculator (Rosenberg et al. 2000). This meta-analysis was based on 52 studies on 31 primate species ( 3 lemur species, 5 New World monkeys, 19 Old World monkeys, and 4 apes; Electronic Supplementary Material [ESM] Table SI).

We used the Fisher transformation to calculate Fisher's $Z$ values and variance from Pearson correlation coefficients using MetaWin v. 2.1 (Rosenberg et al. 2000). We ran five different sets of meta-analyses, one for each of the five predictions (see earlier). We used phylogenetically controlled mixed-effects models on the effect sizes (Fisher's $Z$ values) and their weighed variance, with the restricted maximum likelihood method, using the package metafor (Viechtbauer 2010) in R (R Core Team 2017).

For each of the five data sets, we included three random factors in the model: study ID as based on publication, to control for multiple data obtained from the same study; species ID, to control for multiple data from the same species; and species phylogeny (ESM Figs. S1-S5) to account for potential phylogenetic inertia in the observed behaviors (Blomberg and Garland 2002). We built the phylogenetic trees using the 10ktrees primate phylogeny v.2 (using a consensus tree and the chronogram branch option), accessible at: http://10ktrees.fas.harvard.edu (Arnold et al. 2010). We entered phylogenetic information into our models as a variance-covariance matrix (Nakagawa and Santos 2012). For all models, we printed the profile plots to check if the addition of random factors led to models that could be fully resolved (i.e., the model had a clear maximum). For the datasets on age and dominance rank, we also built a model including sex of the study animal (male or female) as a fixed factor, because in these two data sets we had separate Fisher's $Z$ values for males and females (see earlier).

We ran all meta-analyses using the function rma.mv in metafor (Viechtbauer 2010). We used the following measures to estimate the fit of each model and its degree of heterogeneity: we calculated the generalized/weighted least squares extension of Cochran's Q (for models with random factors only) and the QE test (for models with the fixed factor sex) to compare the observed variance across studies to the expected variance due to sampling error; we calculated the total degree of heterogeneity, $I^{2}$, to measure the extent to which the factors included in the model actually contribute to the variability in the correlation coefficients reported in the literature (Higgins et al. 2003); and we also calculated the degree of heterogeneity that each random factor (study ID, species ID, and species phylogeny) contributed to the total $R^{2}$.

For the data sets on age and dominance rank, we used the Akaike information criterion (AIC) and a log-likelihood ratio test to assess the fit of our fixed-effect models (including sex) in relation to the basic models (with only random factors). We assessed the significance of the fixed factors using the omnibus QM test, which allowed us to test the null hypothesis that the beta coefficients in the model are all equal to zero. We reran the models with the maximum likelihood method, as the log-likelihood ratio test cannot be run with the restricted maximum likelihood method (Viechtbauer 2010). All models contained intercepts. When the inclusion of a fixed factor (sex) was significant, we reran the model excluding the intercept to test for effects within each sex separately.

To test whether our data were affected by publication bias, we present funnel plots for the five models; in addition, we used the regression test for funnel plot asymmetry to detect any significant publication bias. The presence of several data points well outside 
the funnel and a significant test for funnel plot asymmetry could indicate a potential publication bias. As this procedure has been recently criticized (Simonsohn 2017), we also analyzed the relationship between the Fisher's $Z$ values and year of publication of the studies included in each data set (entered as a continuous fixed factor), to explore whether the magnitude of effect sizes changed over the years (Kelly et al. 2018).

As our data sets comprised studies that used different definitions of IGEs (see earlier), we ran five control models, one for each data set, to analyze the effect of definition of IGE. In these analyses we entered the following two variables as fixed factors, one at a time to avoid over-parameterization of the model: 1) definition of IGE (binary: definition provided in the study or not); and 2) distance (continuous: maximum distance between two groups to define an IGE). We ran the second control model on a smaller sample size, as only some studies had used a distance to define an IGE. Definition of IGE and maximum distance to define an IGEs had no significant effect on the Fisher's $Z$ values in the five data sets (all $P>0.28$ ); thus, we excluded these variables from any further analyses. We also wanted to control for the effect of provisioning, as our data sets comprised studies on both provisioned and "wild" animals. However, we never had more than two provisioned studies in each data set and $90 \%$ of these studies were on macaque species. For this reason, we did not run any analysis to control for the effect of provisioning on the Fisher's $Z$ values.

\section{Ethical Note}

There are no ethical implications related to this systematic review. The authors declare they have no conflict of interest.

Data Availability The data set generated and analyzed during the current study is available in the ESM Table SI.

\section{Results}

\section{Publication Bias}

Even though some data points were outside the funnel in the respective funnel plots (ESM Figs. S6-S10), we did not find any consistent indication of publication bias for any of our data sets, as the regression tests for funnel plot asymmetry were all not significant (all $Z<|1.80|$, all $P>0.08$ ) and year of publication of the studies had no significant effect on the Fisher's $Z$ values (all $Z<|1.52|$, all $P>0.13$ ).

\section{Group Size-Aggression Effect}

Cochran's test for heterogeneity was significant ( $\mathrm{Qs}=38.45$, df $=11, P<0.001$ ), suggesting that the variance across studies was greater than the variance due to sampling error. Total heterogeneity was high $\left(I^{2}=78.81 \%\right)$ and it was almost completely due to species ID $\left(I^{2}=78.81\right)$ with a very minor contribution of species phylogeny $\left(I^{2}<0.0001 \%\right)$. The random factor study ID was excluded from this model, 
as no study contributed with more than one data point. The effect size for the group size-aggression relationship was low (0.013) and group size was not significantly related to the proportion of aggressive IGEs a group is involved in (estimate $\pm \mathrm{SE}=$ $0.01 \pm 0.27, Z=0.05, k=12, P=0.96$; Fig. 2).

\section{Group Size-Outcome Effect}

Cochran's test for heterogeneity was significant $(\mathrm{Qs}=34.79, \mathrm{df}=22, P<0.05)$ and total heterogeneity was relatively low $\left(R^{2}=32.71 \%\right)$. The model heterogeneity was almost completely due to study ID $\left(I^{2}=32.71\right)$ with a very minor contribution of species ID $\left(I^{2}<0.001 \%\right)$ and no contribution of species phylogeny $\left(I^{2}=0.00 \%\right)$. We found a moderate/high effect of group size-outcome: groups that were larger compared to their opponents were significantly more likely to win an IGE than smaller groups (estimate $\pm \mathrm{SE}=0.46 \pm 0.12, Z=3.99, k=23, P<0.0001$; Fig. 3).

\section{Age Effect}

Cochran's test for heterogeneity was significant ( $\mathrm{Qs}=78.12$, $\mathrm{df}=7, P<0.0001)$; total heterogeneity was high $\left(I^{2}=96.42 \%\right)$ and due to species phylogeny $\left(I^{2}=96.42 \%\right)$, with almost zero contribution from study ID and species ID (both $R^{2}<0.001 \%$ ). Although the effect size was moderate, the relationship between the age of an individual and its frequency of aggressive participation in BGEs was nonsignificant (estimate $\pm \mathrm{SE}=$ $0.37 \pm 0.83, Z=0.45, k=8, P=0.65$; Fig. 4). When we included "sex" to the model, the model fit did not improve significantly (likelihood ratio test $P=0.48$; AIC random effects model $=22.70$, AIC mixed-effects model $=24.21$ ). Furthermore, the Omnibus

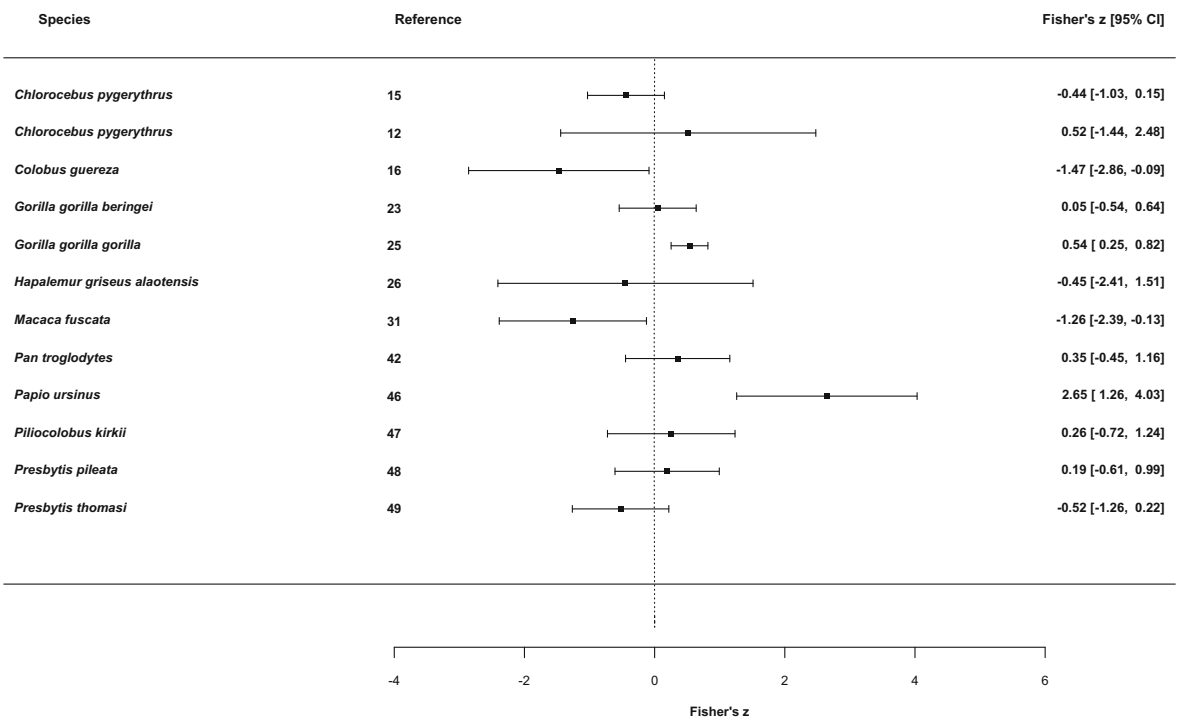

Fig. 2 Forest plot of the Fisher's $Z$ values and 95\% CIs of group size-aggression (correlation between group size and proportion of aggressive IGEs) for the species/populations included in our analyses. Positive Fisher's $Z$ values indicate that larger groups are more aggressive than smaller groups during IGEs. Full details of the numbered references are in the Electronic Supplementary Material. 


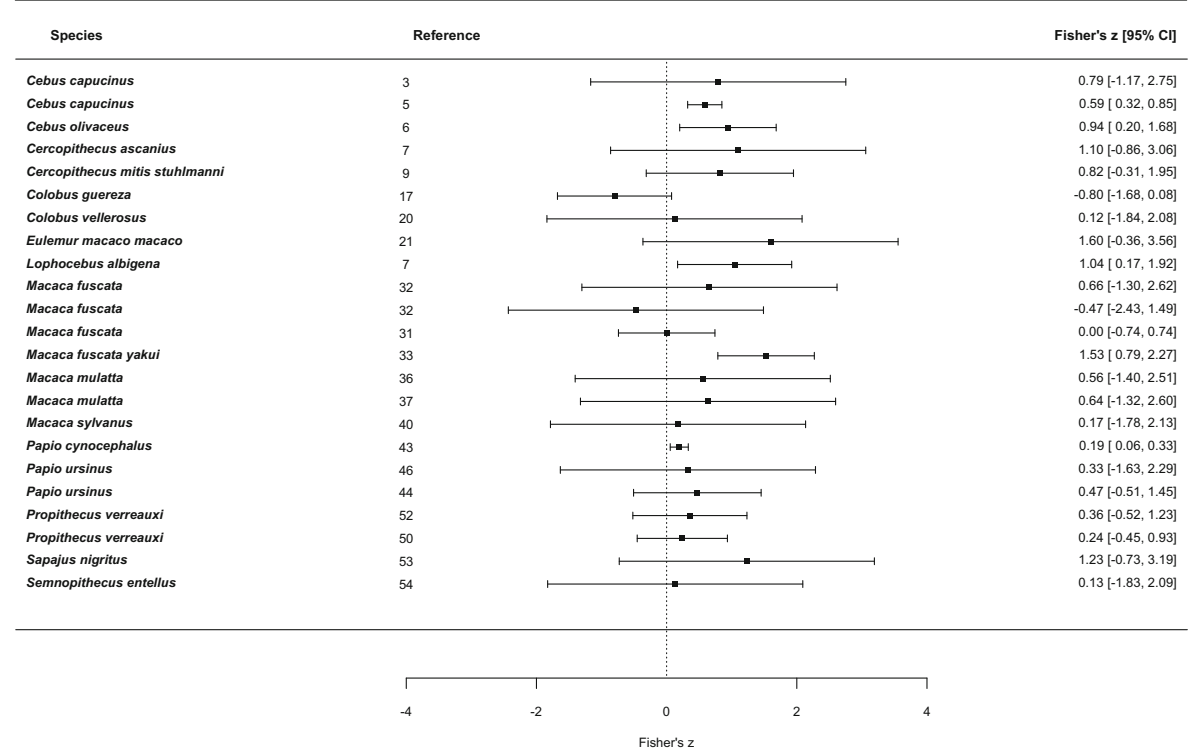

Fig. 3 Forest plot of the Fisher's $Z$ values and 95\% CIs of group size-outcome (correlation group size difference between the two opposing groups and IGE outcome) for the species/populations included in our analyses. Positive Fisher's $Z$ values indicate that the larger of the two opposing groups is more likely to win an IGE than the smaller group. Full details of the numbered references are in the Electronic Supplementary Material.

QM test suggested that the effect sizes for males and females were not significantly different from zero $(\mathrm{QM}=0.31 \mathrm{df}=1, P=0.58)$ and the estimated average effect size for males was not significantly different from that for females (estimate of difference = $0.18, Z=0.55, P=0.58$ ). Thus, the relationship between age and frequency of aggressive participation in IGE did not differ between the sexes.

\section{Dominance Rank Effect}

Cochran's test for heterogeneity was significant (Qs $=116.96$, df $=17, P<0.0001)$; total heterogeneity was high $\left(I^{2}=96.42 \%\right)$ and due to species phylogeny $\left(I^{2}=89.77 \%\right)$, with almost zero contribution from study ID and species ID (both $I^{2}<0.001 \%$ ). The effect size was low and the relationship between the dominance rank of an individual and its frequency of aggressive participation in IGEs was nonsignificant (estimate $\pm \mathrm{SE}$ $=0.05 \pm 0.58, Z=0.09, P=0.94$; Fig. 5). When we included sex in the model, the model fit improved significantly (likelihood ratio test; $P=0.0005$; AIC random effects model $=55.74$, AIC mixed-effects model $=45.64)$. The Omnibus QM test suggested that the effect sizes for males and females were significantly different from zero $(\mathrm{QM}=$ 12.01, $\mathrm{df}=1, P<0.001)$. The estimated average effect size was significantly different between the two sexes (estimate of difference $=0.78, Z=3.47, P<0.001$ ) and it was positive for males and negative for females, suggesting that dominant males were more aggressive during IGEs than subordinates whereas the reverse was true for females. However, neither males nor females on their own showed a significant relationship between dominance rank and frequency of aggressive participation in IGEs (females: estimate $=-0.31, Z=-0.53, P=0.59$; males: estimate $=0.47, Z=0.80, P=0.43$ ). 


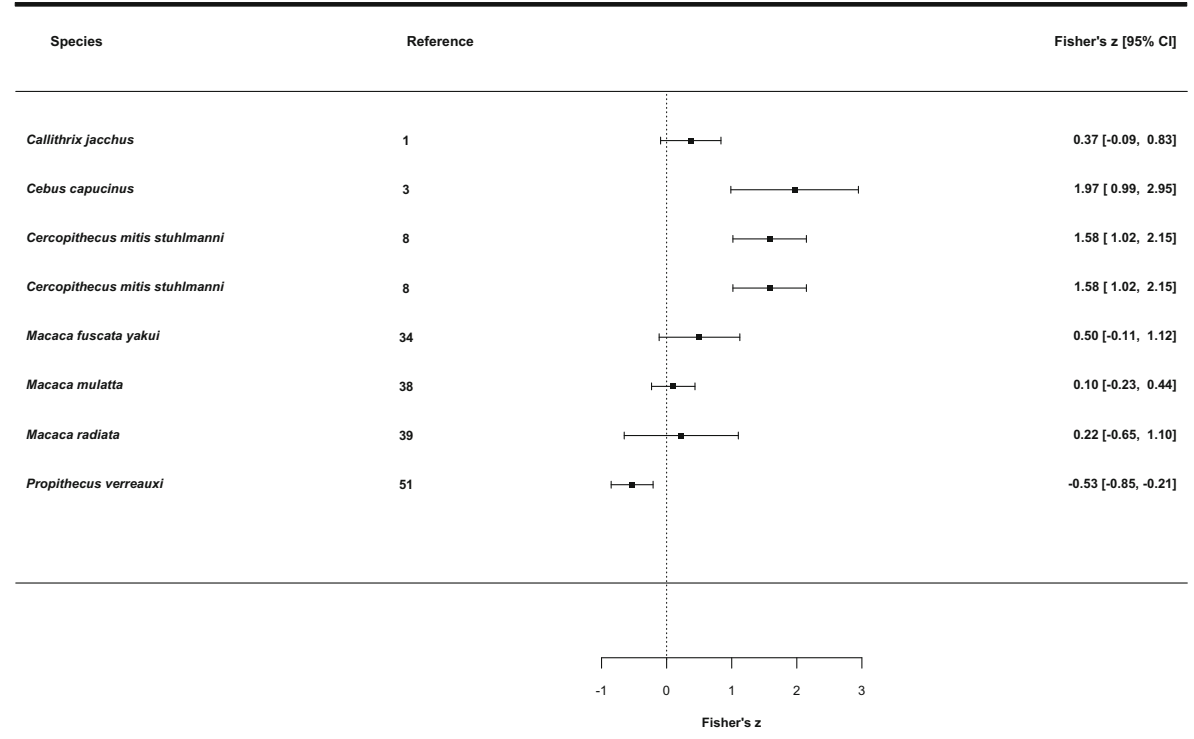

Fig. 4 Forest plot of the Fisher's $Z$ values and 95\% CIs of age (correlation between age and frequency of aggressive participation in IGEs) for the species/populations included in our analyses. Positive Fisher's $Z$ values indicate that older individuals are more aggressive than younger ones during IGEs. Full details of the numbered references are in the Electronic Supplementary Material.

\section{Sex Difference Effect}

Cochran's test for heterogeneity was significant (Qs $=289.21$, $\mathrm{df}=27, P<0.0001)$. Total heterogeneity was high $\left(R^{2}=95.64 \%\right)$ and it was mostly due to species ID $\left(R^{2}=\right.$

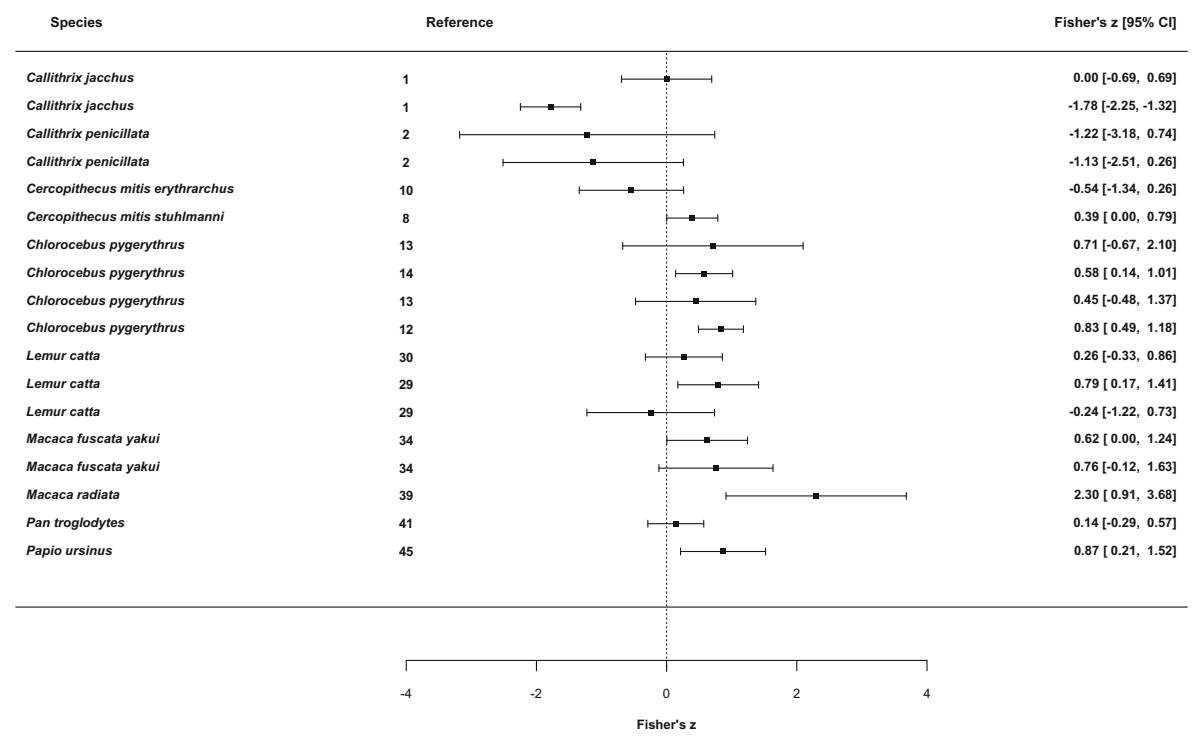

Fig. 5 Forest plot of the Fisher's $Z$ values and 95\% CIs of dominance rank (correlation between dominance rank and frequency of aggressive participation in IGEs) for the species/populations included in our analyses. Positive Fisher's $Z$ values indicate that dominant individuals are more aggressive than subordinates during IGEs. Full details of the numbered references are in the Electronic Supplementary Material. 
$41.64 \%)$ and species phylogeny $\left(R^{2}=48.64 \%\right)$, with a small contribution from study ID $\left(I^{2}=5.36 \%\right)$. Contrary to our prediction, there was no significant relationship between sex of the individual and proportion of aggression displayed during IGEs (estimate \pm $\mathrm{SE}=0.48 \pm 0.41, Z=1.19, k=28, P=0.24$; Fig. 6 ). As the mean effect size for sex differences in aggression was moderate/high, we ran a second analysis removing all the random factors from the model. This second analysis showed that males are significantly more aggressive during IGEs than females (estimate $\pm \mathrm{SE}=0.56 \pm$ $0.14, Z=3.88, P<0.001)$. Taken together, the two analyses indicate that males are more aggressive than females in the primate species represented in our data set, but that the sex difference disappears when controlling for phylogeny.

\section{Discussion}

In our analyses we found support for the hypothesis that, for encounters in which there is numeric disparity between the two opposing groups (based on total number of adults and subadults of both sexes in each group), the larger group is more likely to win a IGE against a smaller group than vice versa. Group size per se was not a predictor of the likelihood that a group was aggressive during IGEs. Interestingly, we found only little support for the hypothesis that dominance rank and age affect how frequently animals enter into aggressive IGEs. Although we found a moderate/high mean effect size for sex differences in aggression during IGEs, potentially providing support for our predictions that males would be more aggressive than females during IGEs, this result disappeared when we controlled for phylogeny and study ID. Thus, the effect of sex differences, although present in the species represented in our data set, cannot be taken

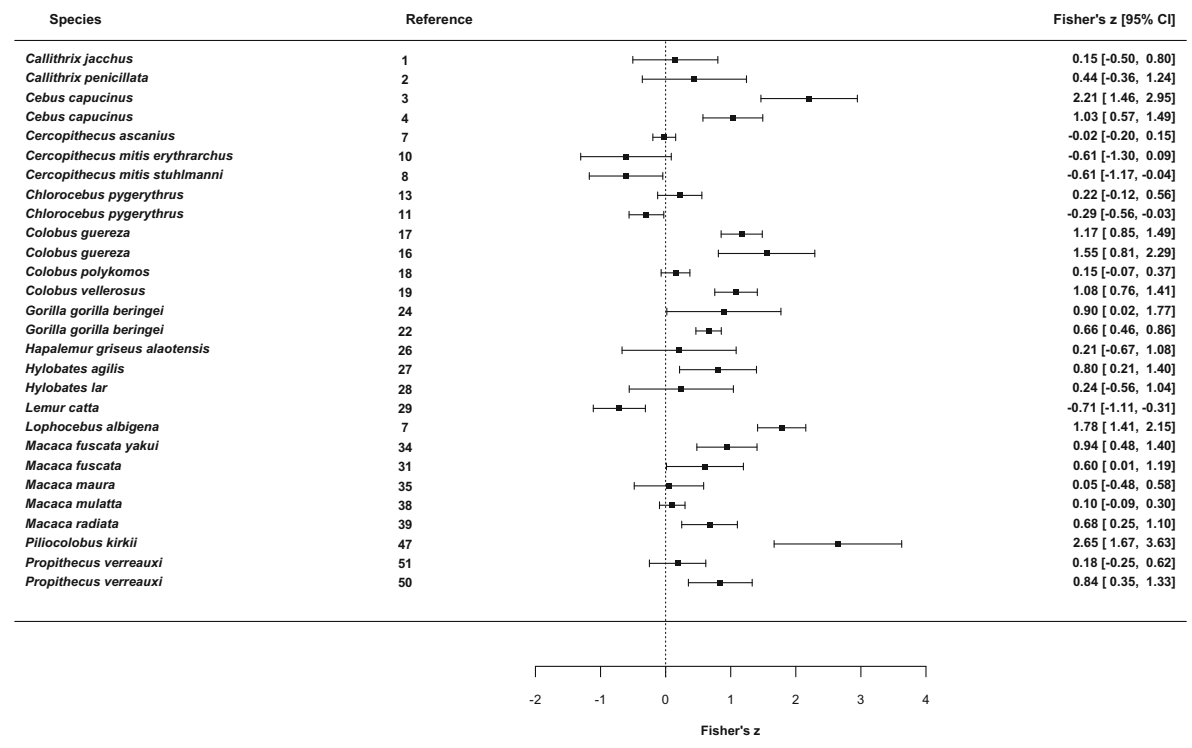

Fig. 6 Forest plot of the Fisher's $Z$ values and 95\% CIs of sex differences (correlation between sex and frequency of aggressive participation in IGEs) for the species/populations included in our analyses. Positive Fisher's $Z$ values indicate that males are more aggressive than females during IGEs. Full details of the numbered references are in the Electronic Supplementary Material. 
as a general effect in primates. Comparative studies, including our own, are often biased in favor of more frequently studied populations or species. Thus, the inclusion of phylogenetic control is essential to determine if the observed result is representative of the entire phylum.

Although the fitness consequences of intergroup competition have rarely been investigated, winning an IGE or being dominant over another group should give fitness-related benefits to the winner (Koenig 2002; Markham et al. 2012; Scarry 2017; Wilson et al. 2012). For example, dominant groups have greater quality and quantity of food in their core areas than subordinate groups in black-and-white colobus monkeys (Colobus guereza: Harris 2006). Our data indicate that relative group size plays an important role in predicting the outcome of IGEs. Contrary to this finding, the number of participants in an IGE does not predict the chance of winning it in vervet monkeys (Chlorocebus pygerythrus; Koch in press) and in bonobos (Pan paniscus; Moscovice et al. in press). In some species neighboring groups can be ranked along a linear dominance hierarchy (Japanese macaque: Sugiura et al. 2000; bonnet macaque, Macaca radiata: Cooper et al. 2004; black-andwhite colobus: Harris 2006; mantled howler monkey, Alouatta palliata: Hopkins 2013) although the long-term stability of these dominance relationships is unclear. However, other studies found IGE outcome to be location dependent: the group closer to the core of their home range is more likely to win an IGE, regardless of numeric differences between the two opposing groups (white-faced capuchin, Cebus capucinus: Crofoot et al. 2008; Verreaux's sifakas, Propithecus verreauxi: Koch et al. 2016). Unfortunately, our data did not allow us to test the role of IGE location and dominance relationship (i.e., previous history of IGEs between opposing groups) on IGE outcome. Moreover, we used group size difference as a predictor of IGE because not enough data on how many individuals in each group participate in IGEs are available in the literature. The actual number of individuals taking part in aR Development Core Teamn IGE may be a stronger predictor of IGE outcome than overall group size. For example, in noncooperatively breeding species with a high degree of genetic diversity between group members, the risk of free riding is expected to increase with group size (Willems et al. 2015), due to reduced capacity to coerce participation in IGEs and low collective defense of resources driven by kin-selection mechanisms. If so, larger groups do not necessarily have a numeric advantage over smaller groups. At the same time, individuals that do not take an active role during aggressive IGEs may still pose a threat to the opposing group, because they might become aggressive if or when the odds of winning an IGE go against their own group. For example, in mountain gorillas (Gorilla gorilla beringei) aggression during IGEs escalated when groups were matched in terms of group size (Mirville et al. 2018). A larger number of studies is necessary before these issues can be addressed by comparative analyses.

Our meta-analysis gave weak/no support to the predictions that dominance rank, age, and sex affect individual differences in participation in IGEs. Contrary to what has been found in previous studies (e.g., Cooper et al. 2004; Majolo et al. 2005; Koch et al. 2016; Lewis et al. in press), dominant individuals and/or males are no more likely to take part in aggressive IGEs than subordinates/females. In relation to age effects, the relationship between age and frequency of BGE aggression might not be linear and may be more accurately described by an inverted U-shaped curve. Juveniles and subadults might be less aggressive during IGEs in order to avoid the risk of engaging in a fight with full-grown opponents. IGE aggression should peak when animals are fully adult and at the peak of their physical and reproductive capacity and gradually 
decrease as they become older. This, together with the difficulty of correctly estimating age in primates when no life history records are available, could partially explain why age did not predict aggression during IGEs.

Large interspecific differences in participation in IGEs exist in relation to developmental trajectories, life history variables, steepness of the dominance hierarchy, and sexual dimorphism. This stresses the importance of increasing our effort to study a larger range of taxa and of comparative analyses. Overall, our lack of support for consistent individual differences across species for frequency of aggression during IGEs in relation to dominance rank, age, and sex may be due to the different, species-specific strategies, and counter-strategies employed by different group members. Selfish interests are expected to be the main driver of behavior during IGEs, at the expense of group-level communal defense of resources (Willems et al. 2015). This is particularly true for multimalemultifemale groups in which intragroup competition for resources is high and results in an unequal benefits/costs ratio across group members. For example, in vervet monkeys females attempt to instigate aggressive IGEs, to out-compete the opposing group and gain access to limiting food sources (Arseneau-Robar et al. 2016), while males are aggressive toward intragroup females that attempt to do so (Arseneau-Robar et al. 2018), because engaging in conflicts with outgroup males can be costly. In this species, dominant males might spend more time trying to stop females from escalating an IGE than actually being aggressive toward the other group. At the same time, subordinate males might be aggressive toward the opposite group to be rewarded by the females and gain mating opportunities. During IGEs, animals may try to maximize their payoff not just in terms of competition with the opposing group but also in terms of possible gains within their group. If so, the predicted greater likelihood that dominant animals aggressively participate in IGEs might be masked by the alternative strategies employed by subordinates. Interactions between groups, involving close-distance aggression, long-distance calls, and intergroup affiliation or avoidance, affect intragroup social dynamics over the short and longterm (Majolo et al. 2016; Mirville et al. in press; Radford et al. 2016; Samuni et al. 2019; Yi 2019). Thus, individual decisions during IGEs can be driven by the complex interplay of the social and ecological benefits that each animal gains/loses during social interactions with its group members and with the opposing group, which will make it hard to detect generalizable commonalities across a wide range of species in meta-analyses such as ours.

Acknowledgements We are extremely grateful to thank Sarie Van Belle, Cyril Grueter, and Takeshi Furuichi for inviting us to contribute to this special volume and to Erik Willems and an anonymous reviewer for very useful comments on an earlier draft of our manuscript. We would like to thank all primatologists who (unknowingly) provided us with data for this study.

Author Contributions BM and JL designed the study, ADBV and LMI collected data, JL and BM analyzed data, and all authors contributed drafting the manuscript.

Open Access This article is licensed under a Creative Commons Attribution 4.0 International License, which permits use, sharing, adaptation, distribution and reproduction in any medium or format, as long as you give appropriate credit to the original author(s) and the source, provide a link to the Creative Commons licence, and indicate if changes were made. The images or other third party material in this article are included in the article's Creative Commons licence, unless indicated otherwise in a credit line to the material. If material is not included in the article's Creative Commons licence and your intended use is not permitted by statutory regulation or exceeds the permitted use, you will need to obtain permission directly from the copyright holder. To view a copy of this licence, visit http://creativecommons.org/licenses/by/4.0/. 


\section{References}

Arnold, C., Matthews, L. J., \& Nunn, C. L. (2010). The 10kTrees website: A new online resource for primate phylogeny. Evolutionary Anthropology, 19(3), 114-118.

Arseneau-Robar, T. J. M., Müller, E., Taucher, A. L., van Schaik, C. P., Bshary, R., \& Willems, E. P. (2018). Male monkeys use punishment and coercion to de-escalate costly intergroup fights. Proceedings of the Royal Society of London B: Biological Sciences, 285(1880), 20172323.

Arseneau-Robar, T. J. M., Taucher, A. L., Müller, E., van Schaik, C., Bshary, R., \& Willems, E. P. (2016). Female monkeys use both the carrot and the stick to promote male participation in intergroup fights. Proceedings of the Royal Society B: Biological Sciences, 283(1843), 20161817.

Arseneau-Robar, T. J. M., Taucher, A. L., Schnider, A. B., van Schaik, C. P., \& Willems, E. P. (2017). Intraand interindividual differences in the costs and benefits of intergroup aggression in female vervet monkeys. Animal Behaviour, 123, 129-137.

Blomberg, S. P., \& Garland, T. (2002). Tempo and mode in evolution: Phylogenetic inertia, adaptation and comparative methods. Journal of Evolutionary Biology, 15(6), 899-910.

Bonanni, R., Valsecchi, P., \& Natoli, E. (2010). Pattern of individual participation and cheating in conflicts between groups of free-ranging dogs. Animal Behaviour, 79(4), 957-968.

Bonadonna (in press). Space use and territory stability in a monogamous singing primate, Indri indri. International Journal of Primatology (this issue).

Brown, M. (2013). Food and range defence in group-living primates. Animal Behaviour, 85(4), 807-816.

Caillaud, D., Levréro, F., Gatti, S., Menard, N., \& Raymond, M. (2008). Influence of male morphology on male mating status and behavior during interunit encounters in western lowland gorillas. American Journal of Physical Anthropology, 135(4), 379-388.

Christensen, C., \& Radford, A. N. (2018). Dear enemies or nasty neighbors? Causes and consequences of variation in the responses of group-living species to territorial intrusions. Behavioral Ecology, 29(5), 1004-1013.

Cooper, M. A., Aureli, F., \& Singh, M. (2004). Between-group encounters among bonnet macaques (Macaca radiata). Behavioral Ecology and Sociobiology, 56(3), 217-227.

Crofoot, M. C. (2013). The cost of defeat: Capuchin groups travel further, faster and later after losing conflicts with neighbors. American Journal of Physical Anthropology, 152(1), 79-85.

Crofoot, M. C., \& Gilby, I. C. (2012). Cheating monkeys undermine group strength in enemy territory. Proceedings of the National Academy of Sciences of the USA, 109(2), 501-505.

Crofoot, M. C., Gilby, I. C., Wikelski, M. C., \& Kays, R. W. (2008). Interaction location outweighs the competitive advantage of numerical superiority in Cebus capucinus intergroup contests. Proceedings of the National Academy of Sciences of the USA, 105(2), 577-581.

Furuichi, T. (2019). Variations in the intergroup relationships between species, between local populations, and within local populations in African great apes. International Journal of Primatology.

Gilby, I. C., Wilson, M. L., \& Pusey, A. E. (2013). Ecology rather than psychology explains co-occurrence of predation and border patrols in male chimpanzees. Animal Behaviour, 86(1), 61-74.

Harris, T. R. (2006). Between-group contest competition for food in a highly folivorous population of black and white colobus monkeys (Colobus guereza). Behavioral Ecology and Sociobiology, 61(2), 317-329.

Higgins, J. P., Thompson, S. G., Deeks, J. J., \& Altman, D. G. (2003). Measuring inconsistency in metaanalyses. BMJ, 327(7414), 557-560.

Hopkins, M. E. (2013). Relative dominance and resource availability mediate mantled howler (Alouatta palliata) spatial responses to neighbors' loud calls. International Journal of Primatology, 34, 1032-1054.

Ishizuka, S., Toda, K., \& Furuichi, T. (2019). Genetic analysis of migration pattern of female bonobos (Pan paniscus) among three neighboring groups. International Journal of Primatology. https://doi.org/10.1007 /s10764-019-00106-w.

Kelly, C. D., Stoehr, A. M., Nunn, C., Smyth, K. N., \& Prokop, Z. M. (2018). Sexual dimorphism in immunity across animals: A meta-analysis. Ecology Letters, 21(12), 1885-1894.

Kitchen, D. M., \& Beehner, J. C. (2007). Factors affecting individual participation in group-level aggression among non-human primates. Behaviour, 144(12), 1551-1581.

Kitchen, D., Seyfarth, R., \& Cheney, D. (2004). Factors mediating inter-group encounters in savannah baboons (Papio cynocephalus ursinus). Behaviour, 141(2), 197-218.

Koch F (in press). Variation in conflict size among vervet monkeys. International Journal of Primatology (this issue).

Koch, F., Signer, J., Kappeler, P. M., \& Fichtel, C. (2016). Intergroup encounters in Verreaux's sifakas (Propithecus verreauxi): Who fights and why? Behavioral Ecology and Sociobiology, 70(5), 797-808. 
Koenig, A. (2002). Competition for resources and its behavioral consequences among female primates. International Journal of Primatology, 23(4), 759-783.

Langergraber, K. E., Watts, D. P., Vigilant, L., \& Mitani, J. C. (2017). Group augmentation, collective action, and territorial boundary patrols by male chimpanzees. Proceedings of the National Academy of Sciences of the USA, 114(28), 7337e 7342.

Lazaro-Perea, C. (2001). Intergroup interactions in wild common marmosets, Callithrix jacchus: Territorial defence and assessment of neighbours. Animal Behaviour, 62(1), 11-21.

Lewis, J. R., Sandel, A. A., Hilty, S, \& Barnett, S. E. (in press). Sex differences explain participation but not outcome of intergroup encounters in a monomorphic primate (Propithecus verreauxi). International Journal of Primatology (this issue).

Majolo, B., de Bortoli Vizioli, A., \& Lehmann, J. (2016). The effect of intergroup competition on intragroup affiliation in primates. Animal Behaviour, 114, 13-19.

Majolo, B., Ventura, R., \& Koyama, N. F. (2005). Sex, rank and age differences in the Japanese macaque (Macaca fuscata yakui) participation in inter-group encounters. Ethology, 111(5), 455-468.

Markham, A. C., Alberts, S. C., \& Altmann, J. (2012). Intergroup conflict: Ecological predictors of winning and consequences of defeat in a wild primate population. Animal Behaviour, 84(2), 399-403.

Maynard Smith, J. (1974). The theory of games and the evolution of animal conflicts. Journal of Theoretical Biology, 47, 209-221.

Maynard Smith, J., \& Parker, G. A. (1976). The logic of asymmetric contests. Animal Behaviour, 24, $159-175$.

Maynard Smith, J., \& Price, G. R. (1973). The logic of animal conflict. Nature, 246(5427), 15-18.

Mech, L. D. (1988). The arctic wolf: Living with the pack. Beverly, MA: Voyageur Press.

Mirville, M. O., Ridley, A. R., Samedi, J. P. M., Vecellio, V., Ndagijimana, F., et al (2018). Low familiarity and similar 'group strength' between opponents increase the intensity of intergroup interactions in mountain gorillas (Gorilla beringei beringei). Behavioral Ecology and Sociobiology, 72, 178.

Mirville, M. O., Ridley, A. R., Samedi, J. P. M., Vecellio, V., Ndagijimana, F., et al. (in press). Intragroup behavioral changes following intergroup conflict in mountain gorillas (Gorilla beringei beringei). International Journal of Primatology (this issue).

Mitani, J. C., \& Watts, D. P. (2005). Correlates of territorial boundary patrol behaviour in wild chimpanzees. Animal Behaviour, 70(5), 1079-1086.

Mitani, J. C., Watts, D. P., \& Amsler, S. J. (2010). Lethal intergroup aggression leads to territorial expansion in wild chimpanzees. Current Biology, 20(12), R507-R508.

Moher, D., Liberati, A., Tetzlaff, J., \& Altman, D. G. (2009). Preferred reporting items for systematic reviews and meta-analyses: The PRISMA statement. Annals of Internal Medicine, 151(4), 264-269.

Moscovice, L. R., Fruth, B., Hohmann, G., Trumble, B. C., \& Jaeggi, A. V. (in press). Dominance or tolerance? Evaluating ecological, social, and hormonal correlates of a prolonged period of intergroup encounters among LuiKotale bonobos. International Journal of Primatology (this issue).

Nakagawa, S., \& Santos, E. S. (2012). Methodological issues and advances in biological meta-analysis. Evolutionary Ecology, 26(5), 1253-1274.

Nunn, C. L. (2000). Collective benefits, free-riders, and male extra-group conflict. In P. Kappeler (Ed.), Primate males: causes and consequences of variation in group composition. Cambridge University Press. 192, 192-204.

Nunn, C. L., \& Deaner, R. O. (2004). Patterns of participation and free riding in territorial conflicts among ringtailed lemurs (Lemur catta). Behavioral Ecology and Sociobiology, 57(1), 50-61.

Parker, G. A. (1974). Assessment strategy and the evolution of fighting behavior. Journal of Theoretical Biology, 47, 223-243.

Payne, H. F., Lawes, M. J., \& Henzi, S. P. (2003). Fatal attack on an adult female Cercopithecus mitis erythrarchus: Implications for female dispersal in female-bonded societies. International Journal of Primatology, 24(6), 1245-1250.

R Core Team (2017). R: A language and environment for statistical computing. R Foundation for Statistical Computing, Vienna, Austria. URL: http://www.R-project.org/.

Radford, A. N., \& Fawcett, T. W. (2014). Conflict between groups promotes later defense of a critical resource in a cooperatively breeding bird. Current Biology, 24(24), 2935-2939.

Radford, A. N., Majolo, B., \& Aureli, F. (2016). Within-group behavioural consequences of between-group conflict: A prospective review. Proceedings of the Royal Society of London B: Biological Sciences, 283(1843). https://doi.org/10.1098/rspb.2016.1567.

Rosenberg, M. S., Adams, D. C., \& Gurevitch, J. (2000). MetaWin 2.0: Statistical software for meta-analysis. Sunderland, MA: Sinauer Associates. 
Samuni, L., Mielke, A., Preis, A., Crockford, C., \& Wittig, R. M. (2019). Intergroup competition enhances chimpanzee (Pan troglodytes verus) in-group cohesion. International Journal of Primatology. https://doi. org/10.1007/s10764-019-00112-y.

Scarry, C. J. (2017). Male resource defence during intergroup aggression among tufted capuchin monkeys. Animal Behaviour, 123, 169-178.

Simonsohn, U. (2017). The funnel plot is invalid because of this crazy assumption: $r(n, d)=0$. Data Colada.

Sterck, E. H. M., Watts, D. P., \& van Schaik, C. P. (1997). The evolution of female social relationships in nonhuman primates. Behavioral Ecology and Sociobiology, 41(5), 291-309.

Sugiura, H., Saito, C., Sato, S., Agetsuma, N., Takahashi, H., et al (2000). Variation in intergroup encounters in two populations of Japanese macaques. International Journal of Primatology, 21(3), 519-535.

Thompson, F. J., Marshall, H. H., Vitikainen, E. I., \& Cant, M. A. (2017). Causes and consequences of intergroup conflict in cooperative banded mongooses. Animal Behaviour, 126, 31-40.

Toda (in press). Demography of female bonobos migrating between unit-groups at Wamba, D.R. Congo. International Journal of Primatology (this issue).

Tórrez-Herrera, L. L., Davis, G. H., \& Crofoot, M. C. (2019). Do monkeys avoid areas of home range overlap because they are dangerous? A test of the Risk Hypothesis in white-faced capuchin monkeys (Cebus capucinus). International Journal of Primatology. https://doi.org/10.1007/s10764-019-00110-0.

Van Belle, S., \& Scarry, C. J. (2015). Individual participation in intergroup contests is mediated by numerical assessment strategies in black howler and tufted capuchin monkeys. Philosophical Transactions of the Royal Society of London B: Biological Sciences, 370, 20150007.

Van Belle, S., \& Estrada, A. (2019) The influence of loud calls on intergroup spacing mechanism in black howler monkeys (Alouatta pigra). International Journal of Primatology. https://doi.org/10.1007/s10764019-00121-x.

Viechtbauer, W. (2010). Conducting meta-analyses in R with the metafor package. Journal of Statistical Software, 36(3), 1-48.

Willems, E. P., Arseneau, T. J. M., Schleuning, X., \& van Schaik, C. P. (2015). Communal range defence in primates as a public goods dilemma. Philosophical Transactions of the Royal Society of London B: Biological Sciences, 370(1683), 20150003.

Willems, E. P., Hellriegel, B., \& van Schaik, C. P. (2013). The collective action problem in primate territory economics. Proceedings of the Royal Society of London B: Biological Sciences, 280(1759), 20130081.

Willems, E. P., \& van Schaik, C. P. (2015). Collective action and the intensity of between-group competition in nonhuman primates. Behavioral Ecology, 26(2), 625-631.

Wilson, M. L., Hauser, M. D., \& Wrangham, R. W. (2001). Does participation in intergroup conflict depend on numerical assessment, range location, or rank for wild chimpanzees? Animal Behaviour, 61(6), 12031216.

Wilson, M. L., Kahlenberg, S. M., Wells, M., \& Wrangham, R. W. (2012). Ecological and social factors affect the occurrence and outcomes of intergroup encounters in chimpanzees. Animal Behaviour, 83(1), 277291.

Wilson, M. L., \& Wrangham, R. W. (2003). Intergroup relations in chimpanzees. Annual Review of Anthropology, 32(1), 363-392.

Wrangham, R. W. (1980). An ecological model of female-bonded primate groups. Behaviour, 262-300.

Wrangham, R. W. (1999). Evolution of coalitionary killing. American Journal of Physical Anthropology, $110(\mathrm{~S} 29), 1-30$.

Yi Y., Fichtel, C., Kim, E., Choe, J. C. (2019). Impacts of intergroup interactions on intragroup behavioral changes in Javan Gibbons (Hylobates moloch). International Journal of Primatology. https://doi. org/10.1007/s10764-019-00116-8. 